\title{
Anticancer Effect of Phellinus linteus; Potential Clinical Application in Treating Pancreatic Ductal Adenocarcinoma
}

\author{
Chang Moo Kang, Dai Hoon Han, Ho Kyoung Hwang, Sung Hoon Choi and Woo Jung Lee*
}

Department of Surgery, Yonsei University College of Medicine, Pancreaticobiliary Cancer Clinic, Institute of Gastroenterology, Severance Hospital, Seoul, Korea

\begin{abstract}
Pancreatic cancer (ductal adenocarcinoma) is one of the most lethal malignancies in gastrointestinal system. Till now, only margin-negative pancreatectomy is known to be the best treatment option for long-term survival. However, the resection rate is reported to be less than $20 \%$. Even in cases of curative resection, most patients generally experience disease recurrence and ultimately die of metastatic disease. Therefore, surgery alone is not enough and adjuvant systemic chemotherapy should be considered for proper management of pancreatic cancer. But, its related toxicity and insufficient oncologic effect requires development of less toxic and more effective alternative treatments for pancreatic cancer. Phellinus linteus (PL), a basidiomycete, is a species of mushroom, which is reported to have the most potent antitumor effect of the basidiomycetes. Recently, there are accumulating researches discovering biologic mechanisms of PL in antitumor effect. However, very few studies were done in pancreatic cancer treatment. In this review, literatures demonstrating the anticancer effects of PL were summarized and some encouraging research data suggesting mushroom component can be alternative approach even in treating pancreatic cancer were reviewed, including our preliminary data suggesting the potential clinical application of PL in treating pancreatic cancer.
\end{abstract}

Keywords: Pancreatic cancer; Phellinus linteus; Basidiomycete; Adjuvant chemotherapy

\section{Introduction}

Pancreatic cancer (ductal adenocarcinoma) is one of the most lethal gastrointestinal malignancies. Complete surgical resection is a basic requirement for long-term survival. However, the resection rate of pancreatic cancer is only $15-20 \%$ because the disease is locally advanced or metastatic at initial diagnosis. Even in cases of curative resection, most patients experience disease recurrence, especially in the liver, and ultimately die of metastatic disease. Gemcitabine has been used as standard chemotherapy for pancreatic cancer [1], but, most clinical trials that have tested combinations with other cytotoxic agents have failed to demonstrate markedly improved oncologic outcomes [2]. In spite of high morbidity, FOLFIRINOX is an emerging chemotherapeutic agent for metastatic pancreatic cancer treatment [3]. However, studies are needed to determine the appropriate dosages and clinical applications, such as use in postoperative adjuvant or neoadjuvant therapy. Therefore development of less toxic and effective alternative treatments for pancreatic cancer is also needed. A potential alternative strategy is to investigate and understand the mechanism of action of natural medicines with anticancer effects.

Phellinus linteus (PL), a basidiomycete, is a species of mushroom whose fruiting body is called sanghuang (Figure 1). This mushroom has been widely used in ancient herbal medicines in Korea, China, and Japan. In 1968, the antitumor activity of polysaccharides from PL was first reported [4]. PL is reported to have the most potent antitumor effect of the basidiomycetes [5]. In the last few decades, the use of PL for suppressing cancer or enhancing immunity [6] has been actively investigated. Biological effects were found to be associated with isolated polysaccharides, proteoglycans and other organic compounds. Isolated compounds and complex extracts from PL inhibit signal pathways in various cancer cells. However, few clinical studies to date have tested the oncologic effects of PL, and only a few cases have demonstrated the therapeutic effect of PL on primary liver cancer. In Japan, a patient with hepatocellular carcinoma and multiple lung metastases was reported to experience complete tumor regression 6 months after treatment with
PL extract [7]. Radiation therapy in combination with PL ingestion resulted in spontaneous remission of hepatocellular carcinoma with skull metastasis in a Korean patient [8].

In this review, we summarize several studies that show the anticancer effects of PL. We also provide our preliminary data that suggests the potential clinical application of PL in treating pancreatic cancer.

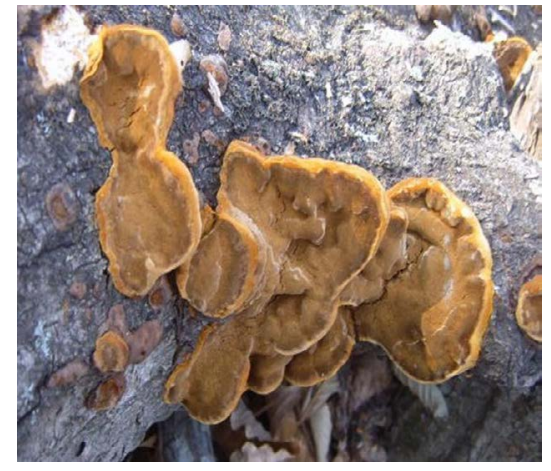

Figure 1: General appearance of Phellinus linteus.

*Corresponding author: Woo Jung Lee, Department of Surgery, Yonsei University, College of Medicine, 50 Yonsei-ro, Seodaemun-gu, Seoul, 120-752, Korea, Tel: +82-2-2228-2120; Fax: +82-2-313-8289; E-mail: wjlee@yuhs.ac

Received March 06, 2013; Accepted April 23, 2013; Published April 30, 2013

Citation: Kang CM, Han DH, Hwang HK, Choi SH, Lee WJ (2013) Anticancer Effect of Phellinus linteus; Potential Clinical Application in Treating Pancreatic Ductal Adenocarcinoma. J Carcinogene Mutagene S9: 001. doi:10.4172/21572518.S9-001

Copyright: ( 2013 Kang CM, et al. This is an open-access article distributed unde the terms of the Creative Commons Attribution License, which permits unrestricted use, distribution, and reproduction in any medium, provided the original author and source are credited. 
Citation: Kang CM, Han DH, Hwang HK, Choi SH, Lee WJ (2013) Anticancer Effect of Phellinus linteus; Potential Clinical Application in Treating Pancreatic Ductal Adenocarcinoma. J Carcinogene Mutagene S9: 001. doi:10.4172/2157-2518.S9-001

\section{Anticancer effects of Phellinus linteus}

The biologically active compoundsin PL are reported to be polysaccharides [9], acidic proteoglycans with mixed $\alpha$ - and $\beta$-linkages, and a $(1 \rightarrow 6)$-branched type $(1 \rightarrow 3)$-glycan [10]. In 1969, Chihara et al. [11] demonstrated that polysaccharide extracts from the basidiomycete fungus PL suppressed tumor growth in vivo. Recently, new furopyranone compounds, phellifuropyranone $\mathrm{A}$ and meshimakobnol $\mathrm{A} / \mathrm{B}$, isolated from fruiting bodies of wild PL, demonstrated antiproliferative activity against mouse melanoma and human lung cancer cells in vitro [12]. However, the molecular mechanisms responsible for the direct antitumor activity have not been fully investigated.

Protein-bound polysaccharides isolated from PL suppressed the proliferation and colony formation of colon cancer cells (SW480). This effect was found to be mediated by cell cycle arrest at G2/M phase and associated with down regulation of cyclin B1 [13]. Isolated low molecular weight compounds from PL such as hispolon demonstrated a dose-dependent inhibition of human epidermoid $\mathrm{KB}$ cell proliferation [14]. Several recent studies demonstrated potential mechanisms of the direct anticancer effects of PL extracts on tumor proliferation, growth and invasiveness (Table 1).

\section{Immunomodulation}

Polysaccharides and proteoglycans extracted from PL might stimulate the proliferation of $\mathrm{T}$ lymphocytes and the humoral immune function, resulting in a secretory and cellular macrophage response. Nonspecific immune functions mediated by natural killer cells and macrophages increased in vivo and in vitro with treatment with PL. PL stimulated humoral immune functions such as T-dependent and -independent primary antibody responses, and acted as a polyclonal activator of B cells. PL exhibited a wider range of immunostimulation and antitumor activity than other polysaccharides isolated from other basidiomycetes [15].

Kim et al. [16] demonstrated that a novel polysaccharide-protein complex extracted from PL markedly increased B-cell proliferation, production of cytokines and nitric oxide from macrophages, and NK cell-mediated killing of YAC-1 lymphoma cells in vitro. These results suggest that $\mathrm{PL}$ is a biological response modifier. In vivo, when HT29 colon cancer cell-bearing mice were treated with proteoglycans extracted from PL, a relative increase in spleen and thymus weights were noted. Significant changes in plasma biochemical parameters showed that PL acted as an immunopotentiator partly through protecting $\mathrm{T}$ cells and enhancing mucosal IgA responses [17]. In human hepatoma (Hep3B) cell-transplanted mice, an extract of a mycelial culture from $\mathrm{PL}$ induced significant reduction of tumor size and increased $\mathrm{T}$ cell numbers, and increased IL-2, IFN- $\gamma$, and TNF- $\alpha$ secretion and NK cell activity and phagocytic ability $[18,19]$. NK cells are especially known for their ability to lyse a variety of tumor cells by exocytosis of perforincontaining granules, subsequently forming lytic pores by perforin on the target cell membrane. In addition, NK cells are responsible for early inhibitory effects on tumor growth and for long-term tumorsuppressive effects $[20,21]$.The importance of innate immunity in pancreatic cancer was recently reiterated by the strong correlation between the absolute numbers of NK cells circulating in patients before chemotherapy and survival and progression-free interval. The average percentage of NK cells before therapy positively correlated with NK cytotoxic lytic units, suggesting that cytotoxic functions of NK cells are important in pancreatic cancer [22].This suggests that PL-induced immunomodulation, especially regarding NK cell activity, needs to be further evaluated in treating cancer patients.

\section{Inhibition of Metastasis}

Chemotherapy is an important therapeutic modality for managing a variety of cancers. However, chemotherapy frequently fails to achieve a satisfactory therapeutic outcome such as complete remission or prevention of distant metastasis with no major chemotherapy-related side effects [23]. Cancer metastasis, in particular, is a major medical problem in treating cancer.

The potential application of PL as an immunotherapeutic agent, especially for cancer metastasis, has been actively investigated. PL alone significantly prolonged the survival rate of $\mathrm{B} 16 \mathrm{~F} 10$ cell-implanted mice, inhibited tumor growth in NCI-H [23] cell-implanted nude

\begin{tabular}{|c|c|c|c|}
\hline Author, year & Direct anticancer effect & Observation & Mechanism \\
\hline Song et al. [56] & $\begin{array}{l}\text { Inhibits tumor growth and } \\
\text { invasion } \\
\text { (colon cancer cells) }\end{array}$ & $\begin{array}{l}\text {-PL significantly inhibited cell proliferation and decreased } \\
\beta \text {-catenin expression in SW480 cells. } \\
\text {-Expression of cyclin D1, TCF/LEF, MMP-9 were also significantly } \\
\text { reduced by PL treatment. }\end{array}$ & Inhibition of Wnt/ß-catenin signaling \\
\hline Li et al. [17] & $\begin{array}{l}\text { Antiproliferative effect } \\
\text { (colon cancer cells) }\end{array}$ & $\begin{array}{l}\text {-PL inhibited HT-29 cell proliferation } \\
\text {-Decreased expression of Reg IV, and EGFR mRNA } \\
\text { - Decreased plasma Reg IV, EGFR, Akt concentration }\end{array}$ & $\begin{array}{l}\text { Down-regulating Reg IV and EGFR } \rightarrow \text { may lead to } \\
\text { disruption of the Reg IV/EGFR/Akt signaling pathway }\end{array}$ \\
\hline Lu et al. [57] & $\begin{array}{l}\text { Inhibits tumor growth } \\
\text { (breast and bladder cancer } \\
\text { cells) }\end{array}$ & $\begin{array}{l}\text {-Hispolon from PL inhibited cancer cell growth } \\
\text { - p21WAF1, a cyclin-dependent } \\
\text { kinase inhibitor, was elevated in hispolon-treated cells } \\
\text { - MDM2, a negative regulator of p21WAF1, was degraded after } \\
\text { hispolon treatment. } \\
\text {-Activated ERK1/2 was recruited to MDM2 leading to MDM2 } \\
\text { degradation }\end{array}$ & $\begin{array}{l}\text { Hispolon from PL ubiquitinates and downregulates } \\
\text { MDM2 via MDM2-recruited activated ERK1/2 and } \\
\text { upregulates p21WAF1 }\end{array}$ \\
\hline Guo et al. [31] & $\begin{array}{l}\text { Cancer growth arrest } \\
\text { (lung cancer cells) }\end{array}$ & $\begin{array}{l}\text {-PL induces cell-cycle arrest at a low concentration. } \\
\text {-Associated with decrease of CDK } 2,4 \text { and } 6\end{array}$ & $\begin{array}{l}\text { PL suppresses the activation of CDK } \rightarrow \text { unable to } \\
\text { form complexes with cyclin } D, E, \text { or } A \rightarrow \text { maintains } \\
\text { phospho-Rb } \rightarrow \text { blockage of cell-cycle progression }\end{array}$ \\
\hline Sliva et al. [36] & $\begin{array}{l}\text { Suppressed growth and } \\
\text { invasive behavior } \\
\text { (breast cancer cells) }\end{array}$ & $\begin{array}{l}\text {-PL inhibits proliferation and colony formation, } \\
\text {-Growth inhibition is mediated by cell cycle arrest at S phase } \\
\text { through upregulation of p27Kip1 } \\
\text { - Suppression of invasion by inhibition of cell adhesion, cell } \\
\text { migration and cell invasion through suppression of uPA secretion }\end{array}$ & $\begin{array}{l}\text { Inhibition of serine-threonine } \\
\text { kinase AKT signaling, upregulation of p27Kip1, and } \\
\text { suppression of uPA }\end{array}$ \\
\hline
\end{tabular}

TCF/LEF, T-cell factor/lymphocyte enhancer binding factor; MMP, matrix metalloprotease; EGFR, epidermal growth factor receptor; ERK1/2, extracellular signal-regulated kinase1/2; CDK, cyclin-dependent kinase; uPA urokinase-plasminogen activator

Table 1: Direct anticancer effects of PL and proposed molecular mechanisms. 
mice, and reduced the frequency of pulmonary metastasis of B16F10 cell melanomas compared to adriamycin, which significantly inhibited tumor growth, but only slightly inhibited metastasis. PL was not directly toxic to cancer cells, suggesting its mechanism is through stimulation of the immune response [24]. In another study [25], PL markedly inhibited melanoma cell metastasis in mice by a direct inhibitory effect on the adhesion to and invasion through the extracellular matrix of cancer cells. In addition, PL increased macrophage NO production. Lee et al. [26] demonstrated that PL might inhibit metastasis at least in part through the regulation of urokinase type plasminogen activator (uPA) associated with tumor cell-induced platelet aggregation. Although PL showed no cytotoxicity against invasive melanoma cells (B16BL6 cells), PL inhibited platelet aggregation induced by B16BL6 cells. It also disrupted the adhesion to gelatin and invasion of B16BL6 cells in a concentration-dependent manner. PL dose-dependently inhibited pulmonary metastatic colonies up to $55.5 \%$ in C57BL/6 mice intravenously injected with B16BL6 cells compared with untreated controls. In addition, PL resulted in concentration-dependent down regulation of the expression of uPA, a key protein in invasion and metastasis of tumor cells.

Recurrence, especially of distant liver metastasis, is a major problem in treating pancreatic cancer following margin-negative pancreatectomy. Recently, FOLFIRINOX successfully demonstrated excellent survival in patients with metastatic pancreatic cancer. However, the significant side effects could limit its general application in clinical practice $[3,27,28]$. Therefore, effective anti-metastatic therapeutic agents need to be further investigated. PL may be a potential candidate as a natural nontoxic agent.

\section{Induction of Apoptosis}

Apoptosis is fundamental process essential for cancer cell death. Deregulation of apoptosis is related to cancer progression. Caspase 3 is important in the propagation of apoptotic signaling. In the caspase cascade, a loss of mitochondrial transmembrane potential results in an increase in the permeability of the mitochondria membrane. Cytochrome C is released to the cytosol, leading to apoptosis [29].

The first description of PL-mediated apoptosis in colon cancer cells was reported in 200413. In this study, polysaccharide from PL (Mesimaw) had an antiproliferative effect on SW480 human colon cancer cells. The effect was mediated through the induction of apoptosis and G2/M cell cycle arrest, and was associated with a decrease in Bcl-2, an increase in the release of cytochrome $\mathrm{C}$, and a reduction in cyclin B1 expression. PL was also found to augment doxorubicin (Dox)induced apoptosis in prostate cancer (LNCaP cells) [30]. PL and Dox do not induce apoptosis, but a combination of low doses of PL and Dox resulted in a synergistic effect on apoptosis induction. In this process, caspases 8, 3, BID were activated. JNK is also activated in response to PL or combination treatment. The antitumor effect derived from apoptosis induction was also demonstrated in mouse and human lung cancer cells [31]. In response to a high-dose PL treatment, lung cancer cells underwent apoptosis accompanied by the activation of caspase 3 and cytochrome $\mathrm{C}$ release. The addition of a caspase inhibitor (Z-VADfmk) completely suppressed apoptotic processes meditated by high-dose PL in lung cancer cells. An in vivo study showed the antitumor property of PL is to induce apoptosis in athymic nude mice model inoculated with prostate cancer DU145 or PC3 cells [32]. Injection of PL caused dramatic tumor regression by triggering apoptotic processes, as demonstrated by histopathology, immunohistochemistry (TUNEL and caspase 3 ), and Annexin V assays. These studies indicated that the upregulation of apoptosis or resensitizing cells to apoptotic stimulation is a promising potential cancer therapy.

\section{Inhibition of Angiogenesis}

Angiogenesis refers to the formation of new blood capillaries from existing ones. This complex process involves degradation of the extracellular matrix, migration and proliferation of endothelial cells, tube formation and sprouting of new capillary branches [33]. Angiogenesis is necessary for both cancer growth and tumor transplantation and metastasis. Therefore, inhibition of angiogenesis can be a potential strategy to suppress tumor growth and metastases.

The anti-angiogenic activity of PL was measured using a Chorioallantoic Membrane (CAM) assay, which is used for detecting in vivo angiogenesis. PL showed potent, dose-dependent anti-angiogenic activity in the CAM assay [34]. However, the mechanism by which PL induces anti-angiogenesis was not fully addressed. A recent study [35] found that PLME (the methanol extract of PL) had anti-angiogenic effects through inhibition of human umbilical vein endothelial cell proliferation, migration, and assembly into capillary-like structures. These effects were mediated by the inhibition of VEGFR-2 phosphorylation. In addition, when human aortic endothelial cells were treated with PL or with conditioned media from the breast cancer cell line MDA-MB-231treated with PL (0-0.5 mg/ml), PL significantly suppressed capillary morphogenesis of human aortic endothelial cells in a dose-dependent manner, compared with conditioned media from cells not treated with PL. This anti-angiogenic effect of PL was reported to be due to suppression of AKT activity, which inhibits secretion of VEGF from breast cancer cells [36]. These results demonstrate that PL might be a novel inhibitor of angiogenesis, suggesting that PL could be a new alternative therapeutic agent for angiogenesis-mediated tumor treatment.

\section{Synergetic Effects with Chemotherapeutic Agents}

A potentially applicable clinical strategy for PL might be using PL as an adjuvant in combination with cytotoxic anticancer agents. However, clinical studies on the feasibility and rationale of PL as a combination anti-cancer treatment are lacking, with only a single in vitro study available. Collins et al. [30] explored the potential combination treatment of Dox and PL against prostate cancer based on studies suggesting that Dox can synergize with TRAIL to elicit cytotoxicity in various tumors [37-40]. PL also inhibited tumor growth. This study showed that PL might act by interfering with the antiapoptotic factor c-FLIP to enhance sensitization of the Dox-mediated apoptotic signal pathway. The results suggest that a combination of PL with a cytotoxic agent could have synergistic anticancer effects in patients. Similarly, Guo et al. [31] demonstrated a synergistic effect of PL in combination with Dox in lung cancer cells. Cells were treated with PL $(0.5 \mathrm{mg} /$ $\mathrm{mL})$, a low dose of Dox $(0.5 \mathrm{mg} / \mathrm{mL})$ alone, or a combination of PL and Dox. Treatment with PL or Dox, or the combination of PL and Dox failed to induce apoptosis in normal lung epithelial cells. Lung cancer cells (LKR or H5800 cells) were also insensitive to either single treatment. However, the combination of the two reagents increased the percentage of DNA fragmentation in cancer cells (more than $20 \%$ ). This indicated the occurrence of apoptosis, suggesting that PL and Dox have a synergistic effect on the induction of apoptosis in lung cancer cells. Another potential use of the genus Phellinus as an adjuvant combination therapy with conventional anticancer treatments was demonstrated by Phellinus igniarius, in the same family as $P$. linteus. $P$. igniarius ethanol extract at 25 or $50 \mathrm{ug} / \mathrm{mL}$ in combination with 
oxaliplatin or 5-fluorouracil synergistically inhibited the proliferation of human hepatocellular carcinoma cells (SK-Hep-1) [41].

\section{Antitumor Activity of Mushroom Derivatives on Pancreatic Cancer}

Till now, no study has been performed about the anticancer effect of PL, however, there are a few experimental data supporting potential anti-tumor activity of mushroom against pancreatic cancer. Simply, although it was not related to PL, another mushroom extract from Cyathusstriatus was shown to inhibit the viability of human pancreatic adenocarcinoma cells; HPAF-II and PL 45. It was noted that growth inhibition could be achieved even in low concentration with short exposure period [42]. The growth of pancreatic cancer BXPC3 cells also were found to markedly be inhibited by $\mathrm{MMH01}$, a compound isolated from Antrodiacinnamomea. In BxPC3 cells, MMH01 treatment resulted in ballooning, a unique morphologic changes known as an early apoptosis. This morphologic changes, but no DNA fragmentation suggested the mode of cell death induced by MMH01 in pancreatic cacnerBxPC3 might be apoptosis-associated events of necrosis [43].

Recently, the underlying potential mechanisms were actively investigated. $\mathrm{Yu}$ et al. [44] demonstrated that antroquinonol, a ubiquinone derivative isolated from a camphor tree mushroom, Antrodiacamphorata, induced a concentration-dependent inhibition of cell proliferation in pancreatic cancer PANC-1 and AsPC-1 cells. This anticancer activity in human pancreatic cancers was found to be through an inhibitory effect on PI3-kinase/Akt/mTOR pathways, which results in down-regulation of cell cycle regulators. It was also noted that antroquinonol induces the cross talk between apoptosis, autophagic cell death and accelerated senescence by up-regulation of $\mathrm{p} 21^{\text {WAF/Cip } 1}$ and K-ras. With regarding cyclin-dependent kinase inhibitor, $\mathrm{p} 21^{\mathrm{WAF} /}$ Cip1, Rosendahl et al. [45] also found that Polysaccharide K (PSK) increases $\mathrm{p} 21^{\mathrm{WAF} / \mathrm{Cip} 1}$ and promotes apoptosis in pancreatic cancer cells. They showed the antiproliferative action of PSK in BxPC-3, PANC-1, MIAPaCa-2, and AsPC-1 was associated with up-regulated cell cycle regulatory $\mathrm{p} 21^{\mathrm{WAF} / \mathrm{Cip} 1}$ and pro-apoptotic protein Bax levels, resulting in cell cycle arrest and induction of apoptosis.

Another study evaluated the antitumor mechanism of protein pound polysaccharide under hypoxia because pancreatic cancer is known to be related with high level of hypoxia. Based on the previous observation that HIF- $1 \alpha$ and Hedgehog (Hh) signal pathway independently regulate the proliferation and invasiveness under the hypoxia [46], Onish et al [47], demonstrated PSK decreased proliferation in PDAC cells under hypoxia, and it definitely inhibited invasiveness of human pancreatic ductal cell lines (ASPC-1, and SUIT2). PSK was also noted to decrease the expression of HIF-1a and hedgehog $(\mathrm{Hh})$ signaling-related molecules under hypoxia, in turn, this inhibition of HIF- $1 \alpha$ and Hh signaling reduced proliferation and invasiveness in PDAC cells under hypoxic condition.

PSK from Basidiomycete Coriolusversicolr also shown to inhibit pancreatic cell line (NOR-P1) by down-regulation of TGF- $\beta 1$ and MMPs. TGF- $\beta 1$, the predominant from in human and the most widely studied isoform of TGF- $\beta$ s, is potent invasion-promoting factors. MMPs are implicated in tumor cell invasiveness. Zhang et al. [48] observed that PSK significantly decreased the invasiveness of NOR-P1 cancer cells in Martrigel-coated filters, and decreased invasion was associated with inhibition of TGF- $\beta 1$, and MMPs.

PSK-induced indirect antitumor activity by augmenting immune system was investigated in early 1990. Noguchi et al. [49] found that
PSK directly augments the proliferation and cytotoxicity of tumorinfiltrating lymphocytes (TILs). TILs defined as lymphocytes found within the tumor tissue and are known to develop as manifestations of the recognition and defense against malignant cells by the host immune system. Therefore, the potential role of TILs has been demonstrated by the prognosis of TILs in pancreatic cancers [50-52]. They observed that DNA synthesis of TILs was increased by incubation with PSK, which was similar to serum level with oral administration of PSK in cancer patients. Although PSK did not affect the cytotoxic activity of TILs against autologous tumor cells in the $4 \mathrm{~h}{ }^{51} \mathrm{Cr}$ release assay, PSK induced high lysability in the $16-\mathrm{h}{ }^{51} \mathrm{Cr}$ release assay. The DNA synthesis of tumor cells was more suppressed by the mixed-tumor cell culture supernatants of TILs cultured with PSK, compared to that of TILs cultured without PSK, suggesting that PSK induced killing activity of TILs by induction of cytotoxic cytokines.

In early 2000, Zhang et al. [53] also demonstrated PSK-mediated NF- $\kappa B$ inhibition enhanced docetaxel-induced apoptosis in human pancreatic cancer cells. Although PSK alone did not show an effect on the viability of human pancreatic NOR-P1 cancer cells, it dosedependently enhanced docetaxel-induced apoptosis, suggesting combination of PSK with a low dose of docetaxel may be a new therapeutic strategy to treat pancreatic cancer patients. However, there is no clinical study evaluating the potential role of mushroom derivatives in clinical practice of treating pancreatic cancer. In 1987, only two cases of unresectable pancreatic cancer responding to combined chemotherapy with cisplatin, PSK, and UFT were reported [54].

\section{Oncologic Impact of Polysaccharides from Phellinus linteus $\left(\mathrm{Aclang}^{\odot}\right)$ in with Postoperative Adjuvant Chemotherapy in Pancreatic Cancer after Surgical Resection: A retrospective pilot study}

In Korea, commercialized polysaccharides from P. linteus (Aclang, Kwang Dong Pharmaceutical Co., Ltd, Korea) are available for clinical use and are covered by medical insurance during postoperative chemotherapy for gastrointestinal malignancy. In this study, we retrospectively investigated the potential oncologic impact of Aclang with postoperative adjuvant chemotherapy in pancreatic cancer with surgical resection.

A total of 103 patients underwent surgical resection for ductal adenocarcinoma of the pancreas at Severance Hospital, Seoul, Korea, from January 2006 through December 2010 . We retrospectively analyzed the medical records of the 53 patients who received postoperative adjuvant chemotherapy without neoadjuvant chemotherapy. In a subset of these patients, Aclang was given concomitantly with postoperative chemotherapy. Two chemotherapy regimens were used: gemcitabinebased therapy and 5-FU-based therapy. Gemcitabine was administered at $1000 \mathrm{mg} / \mathrm{m} 2$ as a 60 -minute intravenous infusion on days 1,8 , and 15 over a four-week cycle. Cisplatin $(70 \mathrm{mg} / \mathrm{m} 2)$ was sometimes added to the gemcitabine infusion on day 1. For 5-FU based chemotherapy, 5 -FU was administered intravenously at $1000 \mathrm{mg} / \mathrm{m} 2$ on days 1,2 , and 3 of the cycle, and carboplatin $(350 \mathrm{mg} / \mathrm{m} 2)$ was added on day 2 of the cycle. Aclang ( $1100 \mathrm{mg}, 550 \mathrm{mg} /$ capsule x 2) was administered orally 3 times per day for $2-4$ months during postoperative chemotherapy. We divided patients into two groups according to Aclang use. The clinicopathological features of the two groups were compared using Mann-Whitney U-tests for continuous data, and are presented as median values (ranges). Chi-squared tests or Fisher's exact tests for categorical variables were used as appropriate. Disease-free and overall 
Citation: Kang CM, Han DH, Hwang HK, Choi SH, Lee WJ (2013) Anticancer Effect of Phellinus linteus; Potential Clinical Application in Treating Pancreatic Ductal Adenocarcinoma. J Carcinogene Mutagene S9: 001. doi:10.4172/2157-2518.S9-001

survival curves were obtained using the Kaplan-Meier method, and differences in survival between groups were compared using a log-rank test. Statistical analysis was conducted using SPSS software version 18 for Windows (SPSS Inc. Chicago, IL, USA). P $<0.05$ was considered to be statistically significant.

\section{Clinicopathological analysis of postoperative polysaccharide Phellinus linteus (Aclang)}

From January 2006 through December 2010, 103 patients underwent pancreatectomy for pancreatic ductal adenocarcinoma. A total of 53 underwent postoperative adjuvant chemotherapy without neoadjuvant chemoradiation therapy and were included in this study. Most patients $(39,73.6 \%)$ received gemcitabine-based postoperative adjuvant chemotherapy, and the remainder received 5FU-based postoperative adjuvant chemotherapy. Aclang was given to 35 patients during postoperative chemotherapy treatment. Median disease-free survival was 6.9 months (95\% Confidence Interval [CI]; 4.6-9.2), and median overall disease-specific survival was 42.3 months $(95 \% \mathrm{CI}$; 22.8-61.8).Our comparative analysis showed no clinicopathological differences between groups (Table 2). Perioperative and pathological characteristics including $\mathrm{T}$-stage, $\mathrm{N}$-stage, lymphovascular invasion, perineural invasion, tumor grade, and margin status were similar between the groups.

\section{Oncologic impact of Aclang with postoperative chemotherapy in pancreatic cancer after surgical resection.}

The anticancer effects of polysaccharides from Aclang were estimated using survival outcomes for each group. Clinicopathological differences were not seen between groups. However, disease-free survival was significantly different for postoperative use of Aclang with adjuvant chemotherapy. While median disease-free survival was 2.8 months (95\% confidence interval; 0.143-5.457) in patients that did not receive Aclang ${ }^{\oplus}$, median disease-free survival was 11.0 months $(95 \%$ CI; 5.329-16.738, $\mathrm{P}=0.017$ ) in patients treated with Aclang. However, overall disease-specific survival was not significantly different between groups (Figure 2).

\section{Summary comments}

To the best of our knowledge, this study is the first clinical report suggesting that PL could potentially be used to treat pancreatic cancer. Despite that postoperative use of Aclang with postoperative adjuvant chemotherapy was observed to significantly delay tumor recurrence, overall disease-specific survival was similar. Moreover, median disease-free survival (DFS) (2.8 months in control group vs. 11.0 months in à Aclang group) appears to be too short and does not appear to be beneficial oncologic impact when comparing to DFS of the 6.9 months in the surgery-alone group vs.13.4 months in patients with surgery followed by the administration of gemcitabine on CONKO-001 trial [55]. Especially, in treating patients with recurrence, most of patients received different chemotherapeutic agents including DDP, oxaliplatinc, TS-1, Xeloda, and combined radiotherapy. In some cases of local liver metastasis, radiofrequency ablations or transarterial chemoembolization with systemic chemotherapy were performed. Various chemotherapeutic agents were heterogeneously applied according to patients' general condition and preference of the oncologist. Therefore, it cannot be emphasized that PL has definite oncologic role in treating pancreatic cancer because this study is

\begin{tabular}{|c|c|c|c|c|}
\hline & & $\begin{array}{l}\text { Control group } \\
(n=18)\end{array}$ & $\begin{array}{l}\text { Aclang group } \\
(\mathrm{n}=35)\end{array}$ & $P$-value \\
\hline Age (years) & & $63.2 \pm 9.5$ & $62.5 \pm 9.0$ & 0.749 \\
\hline Sex & Female/Male & $8 / 10$ & $14 / 21$ & 0.756 \\
\hline Biliary decompression & No/Yes & $12 / 6$ & $20 / 15$ & 0.502 \\
\hline Tumor Location & Head/Body+Tail & $11 / 7$ & 23/12 & 0.590 \\
\hline Resectability ${ }^{1}$ & PR/BR/LA & $14 / 4 / 0$ & $23 / 11 / 1$ & 0.602 \\
\hline Operation & $\mathrm{PD} / \mathrm{DPS} / \mathrm{TP}$ & $10(8)^{*} / 7 / 1$ & $23(21) * / 12 / 0$ & 0.392 \\
\hline Vascular resection ${ }^{2}$ & No/Yes & $16 / 1$ & $29 / 6$ & 0.576 \\
\hline Blood loss (ml) & & $709.4 \pm 556.9$ & $660.2 \pm 423.1$ & 0.667 \\
\hline Transfusion & No/ Yes & $12 / 5$ & $25 / 10$ & 0.726 \\
\hline Operation time (min) & No/Yes & $423.3 \pm 192.2$ & $426.0 \pm 171.9$ & 0.843 \\
\hline Tumor Size (cm) & & $2.7 \pm 1.8$ & $2.9 \pm 1.3$ & 0.585 \\
\hline T-stage & $\mathrm{T} 1 / \mathrm{T} 2 / \mathrm{T} 3 / \mathrm{T} 4$ & $0 / 0 / 17 / 0$ & $1 / 1 / 31 / 2$ & 0.510 \\
\hline $\mathrm{N}$-stage & N0/N1 & $7 / 10$ & $13 / 22$ & 0.964 \\
\hline PNI & No/Yes & $6 / 11$ & $11 / 23$ & 0.781 \\
\hline LVI & No/Yes & $12 / 5$ & $19 / 15$ & 0.655 \\
\hline \multirow[t]{4}{*}{ Tumor Grade } & Well & 6 & 5 & 0.466 \\
\hline & Moderate & 11 & 26 & \\
\hline & Poor & 1 & 3 & \\
\hline & Undifferentiated & 0 & 1 & \\
\hline R0 resection & R0/R1/R2 & $15 / 2 / 0$ & $29 / 3 / 3$ & 0.590 \\
\hline Postoperative chemotherapy & $\begin{array}{l}\text { GEM-based/ } \\
\text { 5FU-based }\end{array}$ & $11 / 7$ & $28 / 7$ & 0.198 \\
\hline LOH (days) & & $22.6 \pm 12.1$ & $19.9 \pm 9.7$ & 0.553 \\
\hline POPF & No/Yes & $15 / 2$ & $34 / 1$ & 0.915 \\
\hline Mortality & No/Yes & $17 / 0$ & $35 / 0$ & NA \\
\hline
\end{tabular}

${ }^{1} 2010$ NCCN guidelines, $P R=$ potentially resectable, $B R=$ borderline resectable, $L A=$ locally advanced

${ }^{2}$ Portal vein wedge resection (1) in the control group vs. portal vein segmental resection, (2) wedge resection, or (3) in the Aclang group. * indicates pylorus-preserving procedure. PNI; perineural invasion, LVI; lymphovascular invasion, LOH; length of hospital stay, POPF; postoperative pancreatic fistula

Table 2: Clinicopathological features of patients in Aclang and control groups. 

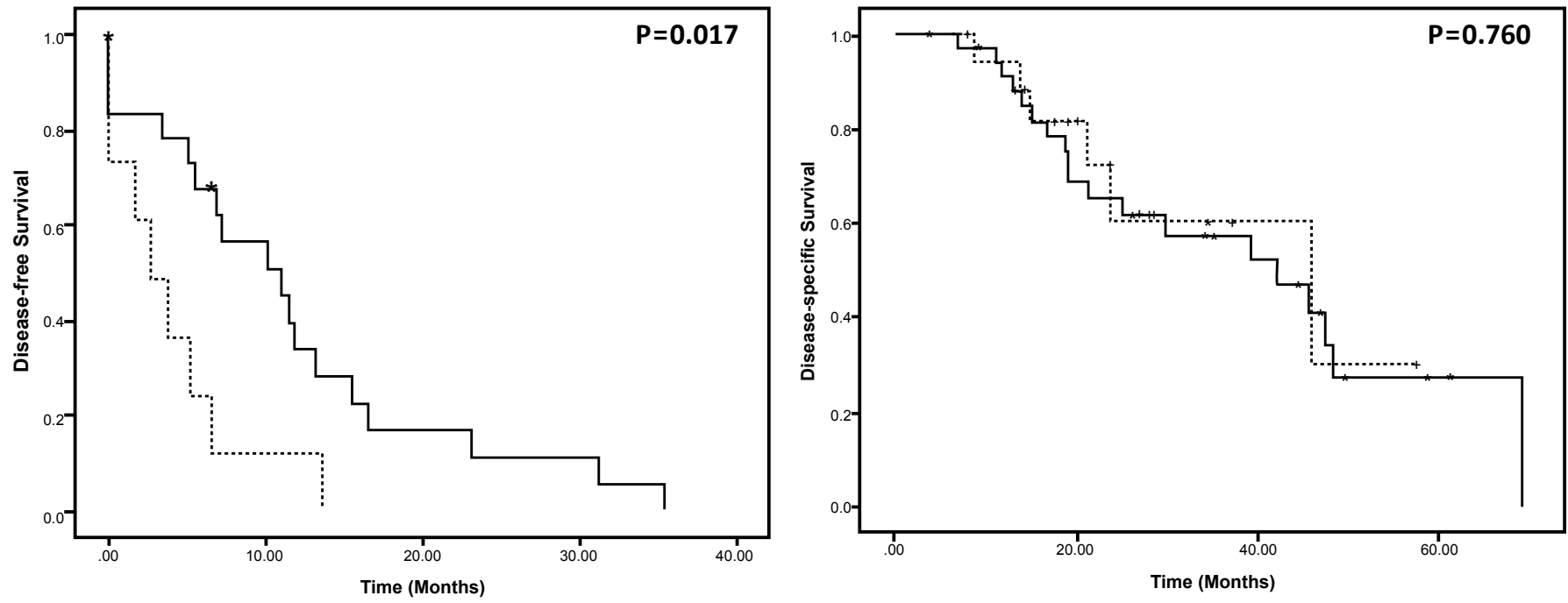

Solid line (Aclang group), dotted line (Control group)

Figure 2: Oncologic outcomes according to use of polysaccharide Phellinus linteus (Aclang®)

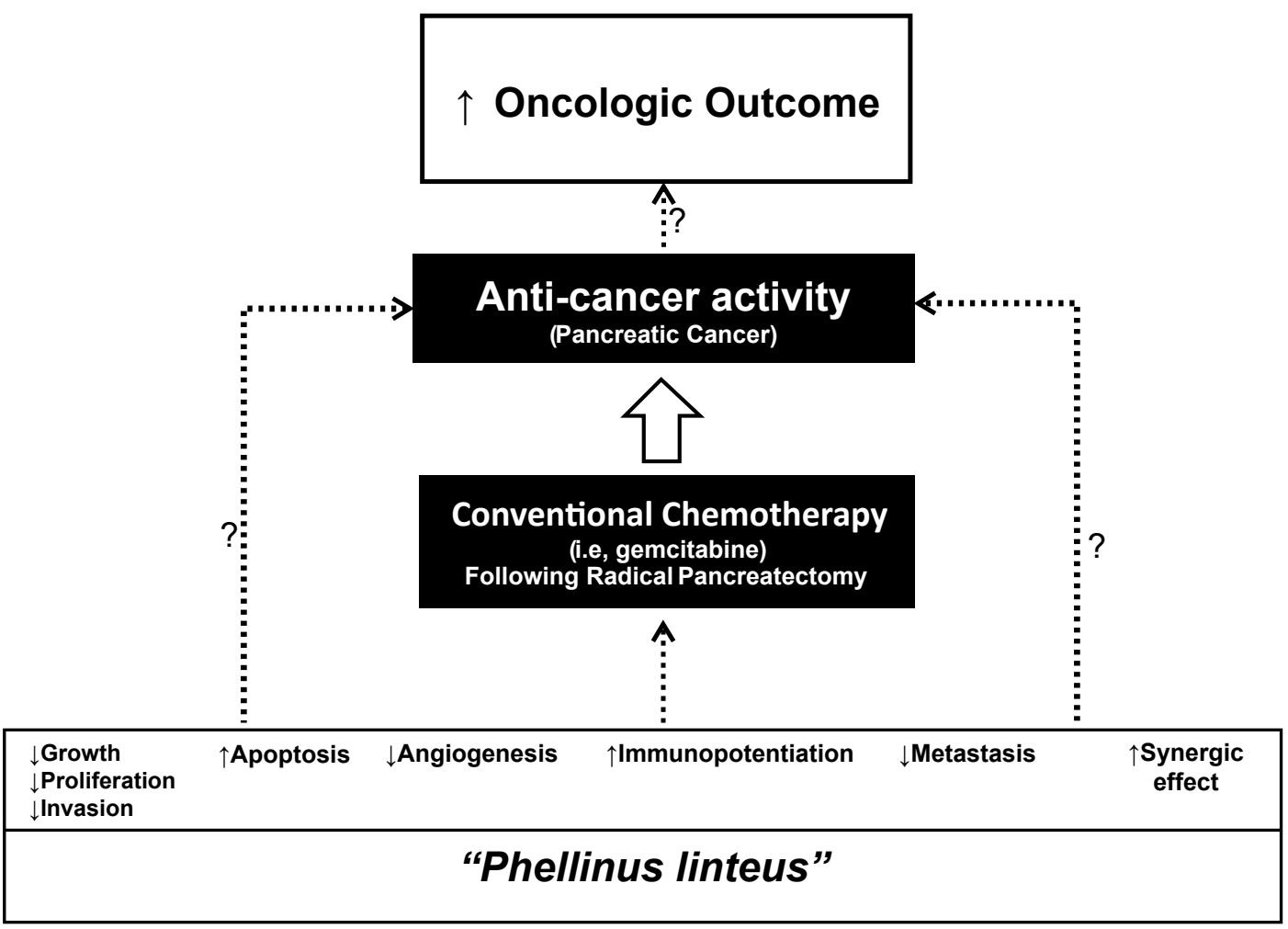

The anticancer effect of Phellinus linteus $(\mathrm{PL})$ has been studied, but use of PL for pancreatic cancer seems to be an unexplored area. The pilot study presented here encurages further investigation on PL for pancreatic cancer treatment.

Figure 3: Unveiled potential oncologic role of Phellinus linteus in pancreatic cancer treatment.

a retrospective and pilot study based on small patients' number. However, as long as this pilot study showed the statistical difference in oncologic outcome was observed, between two groups, and there are several published scientific back ground for PL and some mushroom derivatives from mushroom in treating pancreatic cancer, we cannot overlook this observation. It should be re-evaluated in prospective randomized control study in near future. We cannot be sure that Aclang had anticancer effects in pancreatic cancer. However, our pilot study provides clinical clues for performing future randomized control studies on the potential of PL for treating resected pancreatic cancer. 
Citation: Kang CM, Han DH, Hwang HK, Choi SH, Lee WJ (2013) Anticancer Effect of Phellinus linteus; Potential Clinical Application in Treating Pancreatic Ductal Adenocarcinoma. J Carcinogene Mutagene S9: 001. doi:10.4172/2157-2518.S9-001

\section{Conclusions}

Given the poor survival rates of patients with pancreatic cancer, a critical need exists to develop alternative treatments to improve oncologic outcomes of pancreatic cancer. In spite of accumulating evidence for the antitumor effect of PL and mushroom derivatives, until now, no studies have examined the potential anticancer mechanism of $\mathrm{PL}$ in pancreatic cancer. Clinical research on the potential of PL for pancreatic cancer treatment is sparse. In addition, no sound evidence does exists on the proper dosage and treatment period for PL as an adjuvant agent in managing pancreatic cancer. Therefore, future studies need to validate the oncologic impact of PL on resected pancreatic cancer. In addition, the exact mechanisms of action of PL in pancreatic cancer pathogenesis should be investigated (Figure 3).

\section{References}

1. Burris HA 3rd, Moore MJ, Andersen J, Green MR, Rothenberg ML, et al. (1997) Improvements in survival and clinical benefit with gemcitabine as first-line therapy for patients with advanced pancreas cancer: a randomized trial. J Clin Oncol 15: 2403-2413.

2. Ying JE, Zhu LM, Liu BX (2012) Developments in metastatic pancreatic cancer: is gemcitabine still the standard? World J Gastroenterol 18: 736-745.

3. Conroy T, Desseigne F, Ychou M, Bouché O, Guimbaud R, et al. (2011) FOLFIRINOX versus gemcitabine for metastatic pancreatic cancer. $N$ Engl $J$ Med 364: 1817-1825

4. Ikekawa T, Nakanishi M, Uehara N, Chihara G, Fukuoka F (1968) Antitumo action of some Basidiomycetes, especially Phllinus linteus. Gann 59: 155-157.

5. Wasser SP (2002) Medicinal mushrooms as a source of antitumor and immunomodulating polysaccharides. Appl Microbiol Biotechnol 60: 258-274.

6. Zhu T, Kim SH, Chen CY (2008) A medicinal mushroom: Phellinus linteus. Curr Med Chem 15: 1330-1335.

7. Kojima H, Tanigawa N, Kariya S (2006) A case of spontaneous regression of hepatocellular carcinoma with multiple lung metastases. Radiat Med 24: 139142.

8. Nam SW, Han JY, Kim JI, Park SH, Cho SH, et al. (2005) Spontaneous regression of a large hepatocellular carcinoma with skull metastasis. J Gastroenterol Hepatol 20: 488-492.

9. Song KS, Cho SM, Lee JH, Kim HM, Han SB, et al. (1995) B-lymphocytestimulating polysaccharide from mushroom Phellinus linteus. Chem Pharm Bull (Tokyo) 43: 2105-2108.

10. Kim GY, Park HS, Nam BH, Lee SJ, Lee JD (2003) Purification and characterization of acidic proteo-heteroglycan from the fruiting body of Phellinus linteus (Berk. \& M.A. Curtis) Teng. Bioresour Technol 89: 81-87.

11. Chihara G, Maeda Y, Hamuro J, Sasaki T, Fukuoka F (1969) Inhibition of mouse sarcoma 180 by polysaccharides from Lentinus edodes (Berk.) sing. Nature 222: 687-688.

12. Kojima K, Ohno T, Inoue M, Mizukami H, Nagatsu A (2008) Phellifuropyranone A: a new furopyranone compound isolated from fruit bodies of wild Phellinus linteus. Chem Pharm Bull (Tokyo) 56: 173-175

13. Li G, Kim DH, Kim TD, Park BJ, Park HD, et al. (2004) Protein-bound polysaccharide from Phellinus linteus induces $\mathrm{G} 2 / \mathrm{M}$ phase arrest and apoptosis in SW480 human colon cancer cells. Cancer Lett 216: 175-181.

14. Chen W, He FY, Li YQ (2006) The apoptosis effect of hispolon from Phellinus linteus (Berkeley \& Curtis) Teng on human epidermoid KB cells. J Ethnopharmacol 105: 280-285.

15. Kim HM, Han SB, Oh GT, Kim YH, Hong DH, et al. (1996) Stimulation of humoral and cell mediated immunity by polysaccharide from mushroom Phellinus linteus. Int J Immunopharmacol 18: 295-303.

16. Kim GY, Lee JY, Lee JO, Ryu CH, Choi BT, et al. (2006) Partial characterization and immunostimulatory effect of a novel polysaccharide-protein complex extracted from Phellinus linteus. Biosci Biotechnol Biochem 70: 1218-1226.

17. Li YG, Ji DF, Zhong S, Zhu JX, Chen S, et al. (2011) Anti-tumor effects of proteoglycan from Phellinus linteus by immunomodulating and inhibiting Reg
IV/EGFR/Akt signaling pathway in colorectal carcinoma. Int J Biol Macromo 48: 511-517.

18. Huang HY, Chieh SY, Tso TK, Chien TY, Lin HT, et al. (2011) Orally administered mycelial culture of Phellinus linteus exhibits antitumor effects in hepatoma cell-bearing mice. J Ethnopharmacol 133: 460-466.

19. Shibolet O, Alper R, Zlotogarov L, Thalenfeld B, Engelhardt D, et al. (2004) Suppression of hepatocellular carcinoma growth via oral immune regulation towards tumor-associated antigens is associated with increased NKT and CD8+ lymphocytes. Oncology 66: 323-330.

20. Proudfoot JR (2002) Drugs, leads, and drug-likeness: an analysis of some recently launched drugs. Bioorg Med Chem Lett 12: 1647-1650.

21. Kodama N, Komuta K, Nanba H (2003) Effect of Maitake (Grifola frondosa) D-Fraction on the activation of NK cells in cancer patients. J Med Food 6: 371 377

22. Davis M, Conlon K, Bohac GC, Barcenas J, Leslie W, et al. (2012) Effect of pemetrexed on innate immune killer cells and adaptive immune $T$ cells in subjects with adenocarcinoma of the pancreas. J Immunother 35: 629-640.

23. Salgaller ML, Lodge PA (1998) Use of cellular and cytokine adjuvants in the immunotherapy of cancer. J Surg Oncol 68: 122-138.

24. Han SB, Lee CW, Jeon YJ, Hong ND, Yoo ID, et al. (1999) The inhibitory effect of polysaccharides isolated from Phellinus linteus on tumor growth and metastasis. Immunopharmacology 41: 157-164.

25. Han SB, Lee CW, Kang JS, Yoon YD, Lee KH, et al. (2006) Acidic polysaccharide from Phellinus linteus inhibits melanoma cell metastasis by blocking cell adhesion and invasion. Int Immunopharmacol 6: 697-702.

26. Lee HJ, Lee HJ, Lim ES, Ahn KS, Shim BS, et al. (2005) Cambodian Phellinus linteus inhibits experimental metastasis of melanoma cells in mice via regulation of urokinase type plasminogen activator. Biol Pharm Bull 28: 27-31.

27. Saif MW, Chabot J (2011) Chemotherapy: Metastatic pancreatic cancer--is FOLFIRINOX the new standard? Nat Rev Clin Oncol 8: 452-453.

28. Ko AH (2011) FOLFIRINOX: a small step or a great leap forward? J Clin Onco 29: $3727-3729$

29. Kroemer G, Zamzami N, Susin SA (1997) Mitochondrial control of apoptosis Immunol Today 18: 44-51.

30. Collins L, Zhu T, Guo J, Xiao ZJ, Chen CY (2006) Phellinus linteus sensitises apoptosis induced by doxorubicin in prostate cancer. $\mathrm{Br} \mathrm{J}$ Cancer 95: 282-288.

31. Guo J, Zhu T, Collins L, Xiao ZX, Kim SH, et al. (2007) Modulation of lung cancer growth arrest and apoptosis by Phellinus Linteus. Mol Carcinog 46 : 144-154.

32. Tsuji T, Du W, Nishioka T, Chen L, Yamamoto D, et al. (2010) Phellinus linteus extract sensitizes advanced prostate cancer cells to apoptosis in athymic nude mice. PLoS One 5: e9885.

33. Folkman J (1995) Angiogenesis in cancer, vascular, rheumatoid and othe disease. Nat Med 1: 27-31

34. Song YS, Kim SH, Sa JH, Jin C, Lim CJ, et al. (2003) Anti-angiogenic, antioxidant and xanthine oxidase inhibition activities of the mushroom Phellinus linteus. J Ethnopharmacol 88: 113-116.

35. Lee YS, Kim YH, Shin EK, Kim DH, Lim SS, et al. (2010) Anti-angiogenic activity of methanol extract of Phellinus linteus and its fractions. J Ethnopharmaco 131: $56-62$.

36. Sliva D, Jedinak A, Kawasaki J, Harvey K, Slivova V (2008) Phellinus linteus suppresses growth, angiogenesis and invasive behaviour of breast cancer cells through the inhibition of AKT signalling. Br J Cancer 98: 1348-1356.

37. Keane MM, Ettenberg SA, Nau MM, Russell EK, Lipkowitz S (1999) Chemotherapy augments TRAIL-induced apoptosis in breast cell lines. Cancer Res 59: 734-741.

38. Lacour S, Hammann A, Wotawa A, Corcos L, Solary E, et al. (2001) Anticance agents sensitize tumor cells to tumor necrosis factor-related apoptosis-inducing ligand-mediated caspase-8 activation and apoptosis. Cancer Res 61: 16451651.

39. Mizutani Y, Yoshida O, Miki T, Bonavida B (1999) Synergistic cytotoxicity and apoptosis by Apo-2 ligand and adriamycin against bladder cancer cells. Clin Cancer Res 5: 2605-2612. 
Citation: Kang CM, Han DH, Hwang HK, Choi SH, Lee WJ (2013) Anticancer Effect of Phellinus linteus; Potential Clinical Application in Treating Pancreatic Ductal Adenocarcinoma. J Carcinogene Mutagene S9: 001. doi:10.4172/2157-2518.S9-001

40. Yamanaka T, Shiraki K, Sugimoto K, Ito T, Fujikawa K, et al. (2000) Chemotherapeutic agents augment TRAIL-induced apoptosis in human hepatocellular carcinoma cell lines. Hepatology 32: 482-490.

41. Song TY, Lin HC, Yang NC, Hu ML (2008) Antiproliferative and antimetastatic effects of the ethanolic extract of Phellinus igniarius (Linnearus: Fries) Quelet. J Ethnopharmacol 115: 50-56.

42. Sharvit LE, Wasser SP, Fares F (2012) The effect of culture liquid ethyl acetate mycelium extracts of medicinal mushrooms on the viability of human pancreatic cancer cells. Int J Med Mushrooms 14: 169-179.

43. Chen YJ, Chou CJ, Chang TT (2009) Compound MMH01 possesses toxicity against human leukemia and pancreatic cancer cells. Toxicol In Vitro 23: 418424

44. Yu CC, Chiang PC, Lu PH, Kuo MT, Wen WC, et al. (2012) Antroquinonol, a natural ubiquinone derivative, induces a cross talk between apoptosis, autophagy and senescence in human pancreatic carcinoma cells. J Nutr Biochem 23: 900-907.

45. Rosendahl AH, Sun C, Wu D, Andersson R (2012) Polysaccharide-K (PSK) increases p21(WAF/Cip1) and promotes apoptosis in pancreatic cancer cells. Pancreatology 12: 467-474.

46. Onishi H, Kai M, Odate S, Iwasaki H, Morifuji $\mathrm{Y}$, et al. (2011) Hypoxia activates the hedgehog signaling pathway in a ligand-independent manner by upregulation of Smo transcription in pancreatic cancer. Cancer Sci 102: 1144 1150.

47. Hideya Onishi TM, Fumihiko Nakao, Seiichi Odate, Takashi Morisaki,Mitsuo Katano (2013) Protein-bound polysaccharide decreases invasiveness and proliferation in pancreatic cancer by inhibition of hedgehog signaling and HIF1a pathways under hypoxia. Cancer Letter.

48. Zhang H, Morisaki T, Matsunaga H, Sato N, Uchiyama A, et al. (2000) Proteinbound polysaccharide PSK inhibits tumor invasiveness by down-regulation of TGF-beta1 and MMPs. Clin Exp Metastasis 18: 343-352.
49. Noguchi K, Tanimura H, Yamaue H, Tsunoda T, Iwahashi M, et al. (1995) Polysaccharide preparation PSK augments the proliferation and cytotoxicity of tumor-infiltrating lymphocytes in vitro. Anticancer Res 15: 255-258.

50. Fukunaga A, Miyamoto M, Cho Y, Murakami S, Kawarada Y, et al. (2004) $\mathrm{CD} 8+$ tumor-infiltrating lymphocytes together with $\mathrm{CD} 4+$ tumor-infiltrating lymphocytes and dendritic cells improve the prognosis of patients with pancreatic adenocarcinoma. Pancreas 28: e26-e31.

51. Abe M, Kondo S, Hirano S, Ambo Y, Tanaka E, et al. (2003) Long-term survival after radical resection of advanced pancreatic cancer: a case report with special reference to CD8+ T-cell infiltration. Int J Gastrointest Cancer 33: 107-110.

52. Nobili C, Degrate L, Caprotti R, Franciosi C, Leone BE, et al. (2008) Prolonged survival of a patient affected by pancreatic adenocarcinoma with massive lymphocyte and dendritic cell infiltration after interleukin-2 immunotherapy. Report of a case. Tumori 94: 426-430

53. Zhang H, Morisaki T, Nakahara C, Matsunaga H, Sato N, et al. (2003) PSKmediated NF-kappaB inhibition augments docetaxel-induced apoptosis in human pancreatic cancer cells NOR-P1. Oncogene 22: 2088-2096.

54. Sohma M, Kitagawa T, Okano S, Utsumi M, Mutoh E, et al. (1987) [Two case of unresectable pancreatic cancer responding to combined chemotherapy with cisplatin, PSK and UFT]. Gan To Kagaku Ryoho 14: 1926-1929.

55. Oettle H, Post S, Neuhaus P, Gellert K, Langrehr J, et al. (2007) Adjuvan chemotherapy with gemcitabine vs observation in patients undergoing curativeintent resection of pancreatic cancer: a randomized controlled trial. JAMA 297: 267-277.

56. Song KS, Li G, Kim JS (2011) Protein-bound polysaccharide from Phellinus linteus inhibits tumor growth, invasion, and angiogenesis and alters Wnt/betacatenin in SW480 human colon cancer cells. BMC Cancer 11: 307.

57. Lu TL, Huang GJ, Lu TJ, Wu JB, Wu CH, et al. (2009) Hispolon from Phellinus linteus has antiproliferative effects via MDM2-recruited ERK1/2 activity in breast and bladder cancer cells. Food Chem Toxicol 47: 2013-2021.
This article was originally published in a special issue, Pancreatic Ductal Adenocarcinoma handled by Editor(s). Dr. Toshiyuki Ishiwata, Nippon Medical School, Japan 